
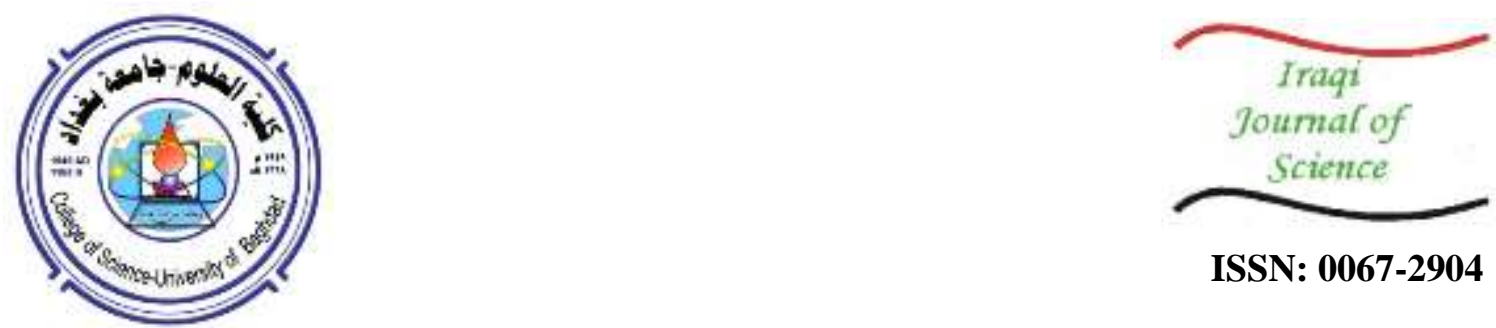

ISSN: 0067-2904

\title{
Immunocytochemical assessment of FKBP51 and Glucocorticoid receptor localization in asthmatic patients
}

\author{
Sura F.Alsaffar*1, Jabbar H. Yenzeel ${ }^{1}$, Haider F.Ghazi ${ }^{2}$ \\ ${ }^{1}$ Department of Biology, college of science, Baghdad University, Baghdad, Iraq. \\ ${ }^{2}$ Department of Microbiology, College of medicine, Al-nahrain University, Baghdad, Iraq
}

Accepted: 27/7/2019

\begin{abstract}
Asthma is a chronic inflammatory disease affecting $5 \%$ of the world population. FKBP51 is an important immunophilin modular protein of the glucocorticoid receptor (GC).

The aim of the present study was to evaluate the levels and immunocytochemical distribution of FKBP51 and GR in lymphocyte cells of asthmatic patients, by use of immunocytochemistry method, and to assesslevels ofstress hormones (cortisol and ACTH) by radioimmuniassay (RIA).

The results showed significantly increased nuclear localization and decreasedcytoplasmic distribution of FKBP51, while they showed a significant increase in nuclear localization and a non-significant decrease in cytoplasmic distribution of GRin asthmatic patients $(\mathrm{P}<0.05)$.

Cortisol and ACTH levels were also measured and showedinsignificant increases $(\mathrm{P}<0.05)$ in steroid treated $(338.85 \pm 139.5 \mathrm{mMol} / \mathrm{L}, 35.05 \pm 3.77 \mathrm{ng} / \mathrm{ml}$, respectively)and non steroid treated asthmatics $(280.5 \pm 74.6 \mathrm{mMol} / \mathrm{L}, 32.0 \pm 6.43$ $\mathrm{ng} / \mathrm{ml}$, respectively)as compared with the control group $(234.33 \pm 29.13 \mathrm{mMol} / \mathrm{L}$, $29.0 \pm 7.02 \mathrm{ng} / \mathrm{ml}$, respectively).
\end{abstract}

Keywords: Asthma, FKBP51, Glucocorticoid Receptor, ACTH, Cortisol.

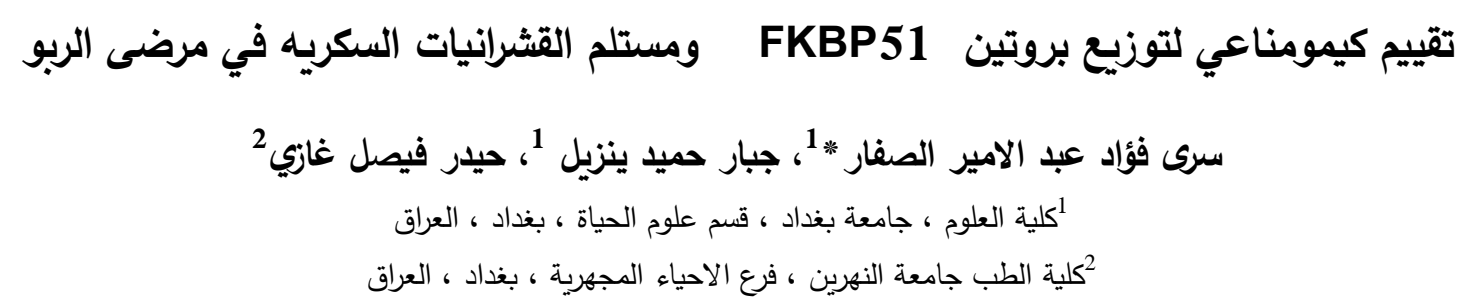

\footnotetext{
الخلاصه

الربو مرض التهابي مزمن , يصيب حوالي 5 \% من سكان العالم KBP51 ـ بروتين منظم لستلم

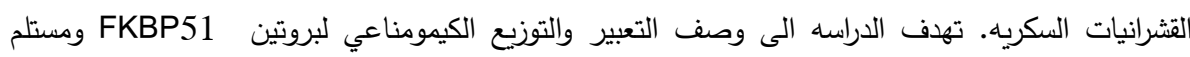

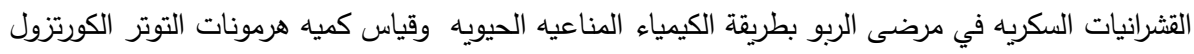
والهزمون المحفز لقشرة الكظربطريقة التقدير المناعي الاشعاعي.

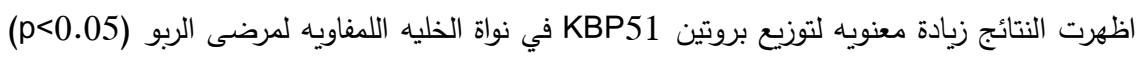

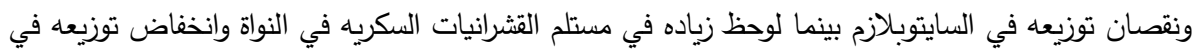




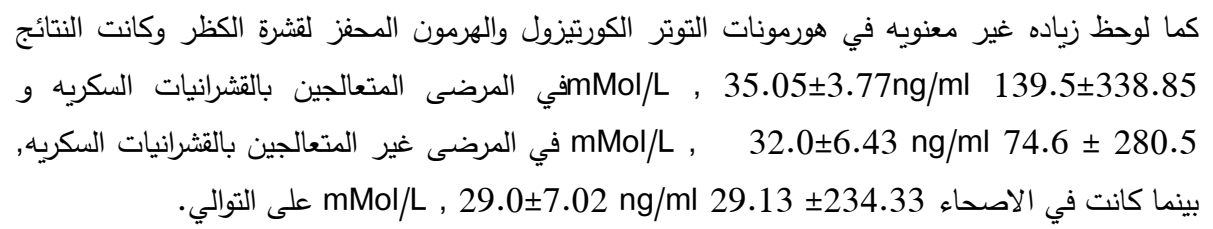

\section{Introduction}

Asthma could be defined as a chronic airway inflammation which is often associated with eosinophilic, TH2-mediated immunopathology. The 2018 Global Initiative for Asthma (GINA) guidelines categorize asthma severity as intermittent, persist mild, persist moderate, and persist severe. Severity is assessed retrospectively from the level of treatment required to control symptoms and exacerbations[1]

Glucocorticoid receptor (GR) belongs to the nuclear receptor superfamily and is present in the cytoplasm as a part of a heterocomplex with Hsp90dimer, p23 and the high molecular weight immunophilins (IMMs), FKBP51 or FKBP52. At the molecular level, glucocorticoid effects depend on the binding of the hormone to the GR in the cytoplasm and their translocation to the nucleus where they interact with glucocorticoid responsive elements (GRE) of different genes and inhibit the transcription of pro-inflammatory genes.

FKBP51 (FK506-binding protein 51) is a member of the immunophilin family of proteins. It is an important regulator of immunity, steroidal physiology, and basic cellular processes of protein folding and trafficking [2].

In humans, evidence for FKBP51-mediated GC resistance has been found. High levels of FKBP51 correlate with resistance to GC therapies for asthma[3] and chronic obstructive pulmonary disease, while diagnostic assays are being developed using FKBP51 as a marker of GC sensitivity[4]

Adrenocorticotropic hormone (ACTH), or corticotropin, is a 39 amino acid peptide hormone produced by cells of the anterior pituitary gland and carried by the peripheral circulation to its effector organ (the adrenal cortex) where it stimulates the synthesis and secretion of glucocorticoids, mineralocorticoids and adrenal androgens [5] .

ACTH is secreted in response to corticotropin-releasing hormone (CRH). ACTH levels, similar to cortisol, vary in an endogenous circadian rhythm, reaching a peak in the morning (about 8 AM) and declining throughout the day. The synchrony between ACTH and cortisol secretion is maintained by glucocorticoids signaling in a negative feedback manner (the anterior pituitary to inhibit further ACTH secretion), which prevents a chronic rise in glucocorticoid levels [6]. Cortisol is a naturally occurring pregnane corticosteroid and is also known as 11 $\beta, 17 \alpha, 21$-trihydroxypregn-4-ene-3,20-dione. It is a steroid hormone from the glucocorticoid class of hormones produced in humans from cholesterol in the zona fasciculata of the adrenal cortex (The name cortisol is derived from adrenal cortex). It is released in response to low blood-glucose concentration and physical and emotional stress [7]. The synthesis of cortisol in the adrenal gland is stimulated by the anterior lobe of the pituitary gland with ACTH. Glucocorticoids (GC) belong to the steroid family and are synthesized by enzymatic processing of cholesterol, mainly in the adrenal glands as well as in keratinocytes and intestinal epithelial cells [8].

\section{Material and methods}

This case control study recruited asthma patients $(n=75)$ aged 18-75 years and healthy control $(\mathrm{n}=30)$. The diagnosis of asthma was established using the American Thoracic Society (ATS) doctor's diagnosis and evidence of variable airflow obstruction. Patients were recruited from the out-patient clinic at the Department of Respiratory Diseases, AL -Imamain Al-Kadhumain Teaching Hospital in Baghdad. They were prescribed with a maintenance inhaled corticosteroid treatment and remained uncontrolled with an Asthma Control Test (ACT) <16 [9].

\section{Blood samples}

Venous blood samples were collected in EDTA anti-coagulated tubes and used for lymphocyte separation according to the Isopaque-ficoll technique originally described by Boyum in 1968 [10, 11]. The separated lymphocytes were mounted on precoated positively charged slides. Percentage of peripheral blood lymphocytes (PBLs) reactivity was semi quantified by an immunocytochemical method andFKBP51(antibodies-online GmbH /Aachen Germany) and GR (biorbyte LLC./UK)were tested by the immunoperoxidase staining method [12] using the super sensitive IHC detection staining 
system kit (biorbyte LLC./UK). Slides were examined under 400X-magnification power of light microscope (ZEISS). The dark brown staining identified positive labeled cells (see Figures-1, 2).

Hormone assay: ACTH and cortisol hormones were measured by radioimmuniassay (RIA) method by using Beckman coulter RIA kits, USA.

\section{Statistical analysis}

The percentage of the expressionfor each of the tested markers on lymphocytes were calculated by a simple calibration of the percentage of reactivity as in the following formulas: Percentage of nuclear expression $=($ No. of positive nuclear cells/ total No. of cells $) \times 100 \%$, and Percentage of cytoplasmic expression $=($ No. of positive cytoplasmic cells/ total No. of cells $) \times 100 \%$.

Statistical differences were analyzed using Independent sample-test. P-values $<0.01$ were considered statistically significant. Simple linear regression was used to assess the relationship between studied variables.

\section{Results}

Nuclear expression of GR in lymphocytes showed a highly significant increase in asthmatic groups compared with the control group, and the expression was insignificantly higher in steroid treated patients than that in steroid free patients(Figure -3).

Immunocytochemical distribution results of GR and FKBP51 are illustrated in Table-1.

GR cytoplasmic expression in lymphocyte showed a highly significant decrease in asthmatic patients in comparison with the control subjects, but there were no significant differences among patient groups (Figure- 4).

Table 1- Glucocorticoid receptor and FKBP51 immunocytochemical expression in lymphocytes.

\begin{tabular}{|c|c|c|c|}
\hline \multirow{2}{*}{} & \multirow{2}{*}{ Controls } & \multicolumn{2}{|c|}{ Patients } \\
\cline { 3 - 4 } & & $\begin{array}{c}\text { Cs } \\
\text { Mean } \pm \text { SE }\end{array}$ & $\begin{array}{c}\text { Cs free } \\
\text { Mean } \pm \text { SE }\end{array}$ \\
\hline GR cytoplasmic & $57 \pm 3$ & $16 \pm 3$ & $14 \pm 5$ \\
\hline GR nuclear & $15.8 \pm 1.15$ & $32.58 \pm 1.8$ & $29.14 \pm 2.76$ \\
\hline FKBP51 cytoplasmic & $19 \pm 4$ & $20 \pm 3$ & $25 \pm 6$ \\
\hline FKBP51 nuclear & $38 \pm 3$ & $55 \pm 3$ & $52 \pm 5$ \\
\hline
\end{tabular}

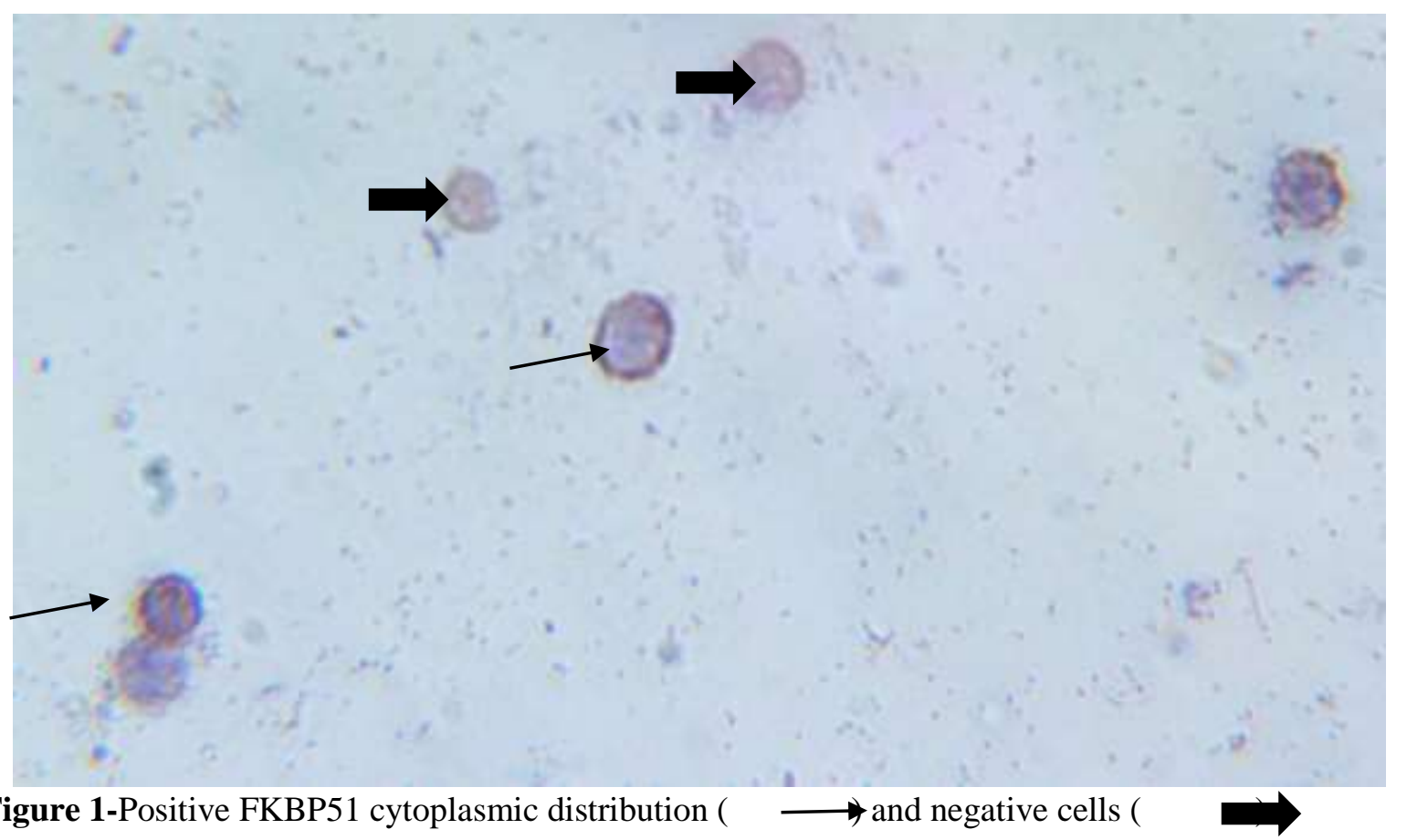




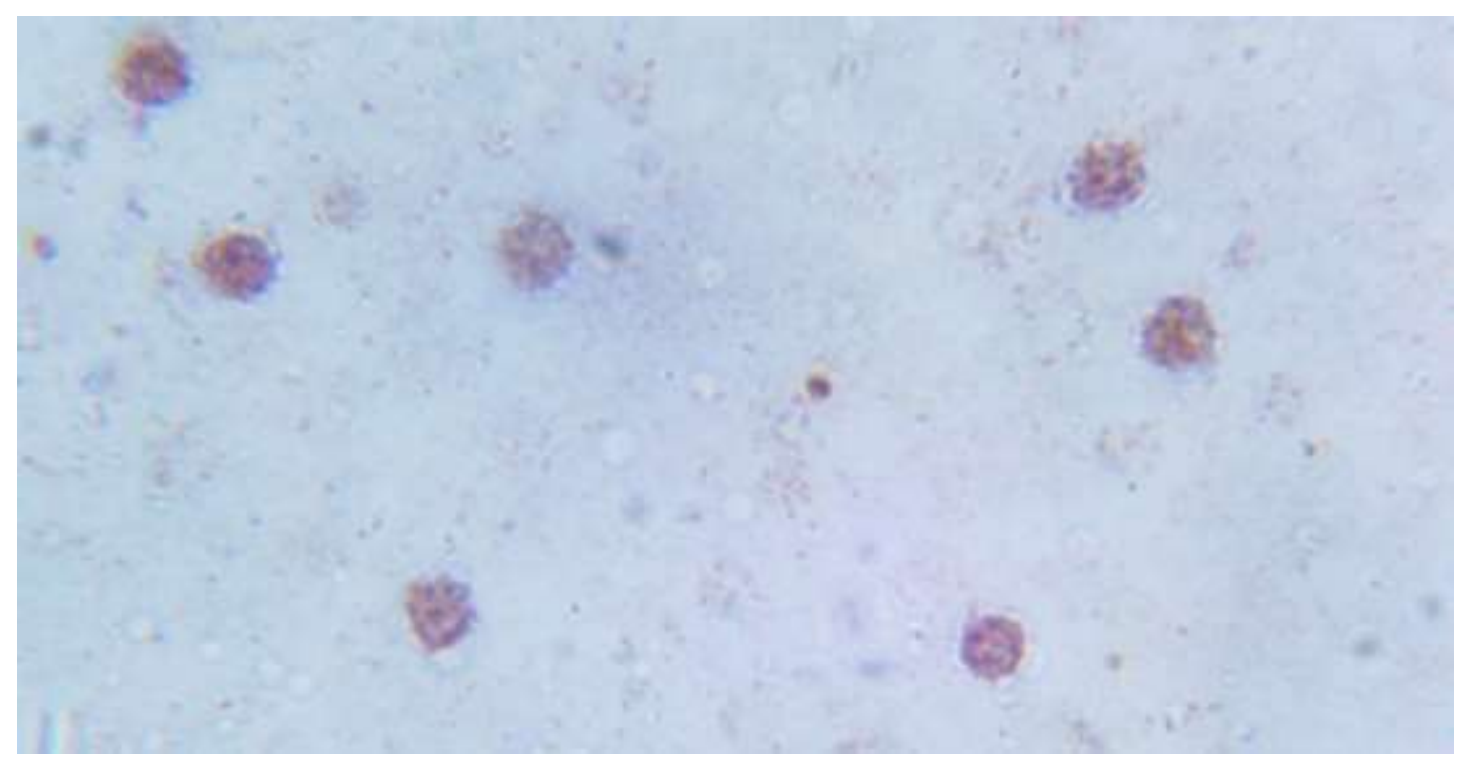

Figure 2- Positive GR nuclear distribution.

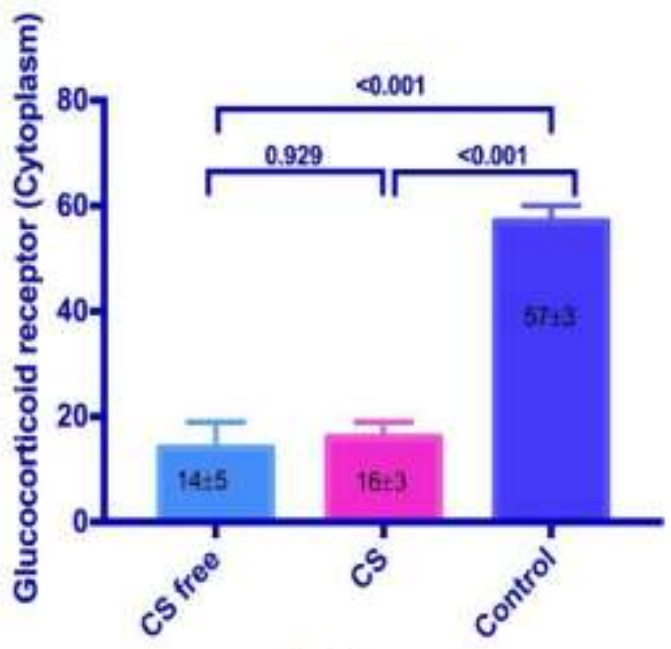

Study groups

Figure 3-Differences in percentages of GR cytoplasmic distribution among the studied groups".

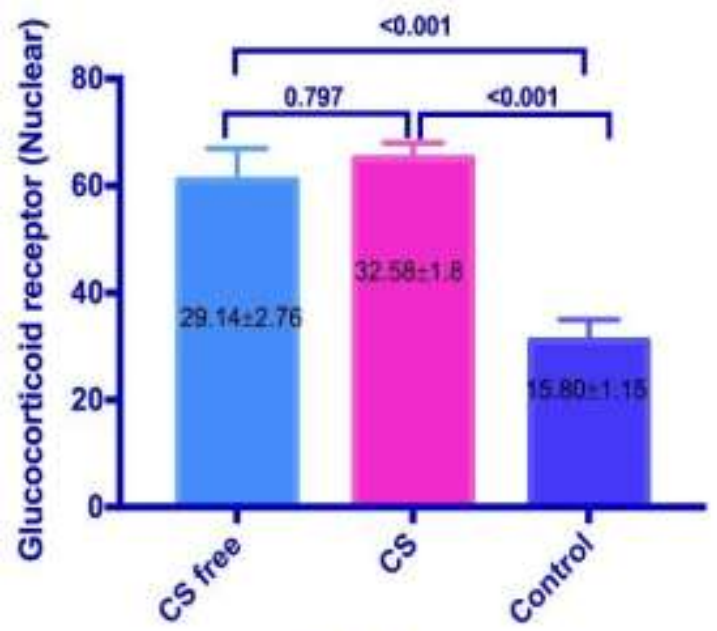

Study groups

Figure 4- Glucocorticoid receptor nuclear distribution percentage in lymphocytes. 


\section{Immunocytochemical FKBP51 expression in lymphocytes}

Nuclear FKBP51 localization in lymphocytes was significantly increased in steroid treated asthmatics and highly significantly increased in steroid free asthmatics when compared with the control (Figure$5)$.

FKBP51 expression in lymphocyte cytoplasm demonstrated no significant differences between patient groups and controls (Figure-6).

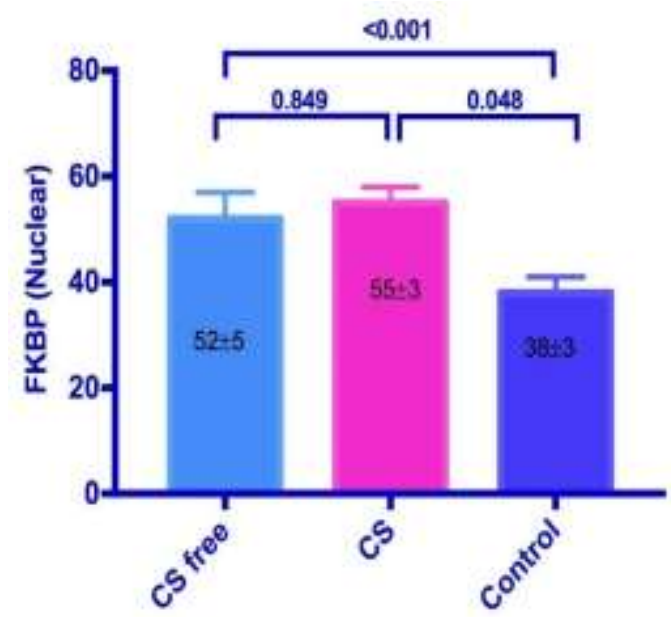

\section{Study groups}

Figure 5- FKBP51 nuclear expression in lymphocytes.

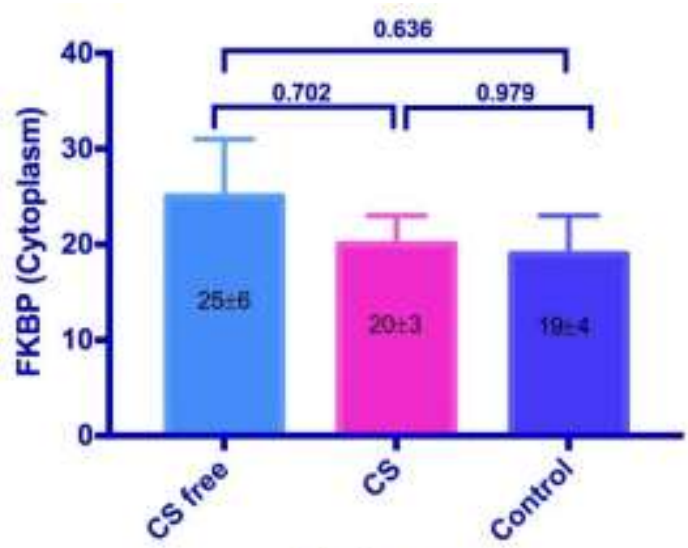

Study groups

\section{Hormones}

Figure 6- FKBP51 cytoplasmic expression in lymphocytes.

\section{CortisolandAdrenocorticotropic hormone}

The mean cortisol concentrations in steroid treated patients, steroid free patients and control subjects were $338.85 \pm 139.5 \mathrm{mMol} / \mathrm{L}, 280.5 \pm 74.6 \mathrm{mMol} / \mathrm{L}$ and $234.33 \pm 29.13 \mathrm{mMol} / \mathrm{L}$, respectively, as clarified in Table-2.

Cortisol hormone results demonstrated no significant differences between the studied groups (Figure7).

Table 2- Mean \pm SE concentrations of cortisol and ACTH hormones in patients and control groups.

\begin{tabular}{|c|c|c|c|}
\hline \multirow{2}{*}{ Hormones } & \multirow{2}{*}{ Controls } & \multicolumn{2}{|c|}{ Patients } \\
\cline { 3 - 4 } & & Cs & Cs free \\
\hline Cortisol $(\mathbf{m M o l} / \mathbf{L})$ & $234.33 \pm 29.13$ & $338.85 \pm 139.5$ & $280.5 \pm 74.6$ \\
\hline ACTH $(\mathbf{n g} / \mathbf{m l})$ & $29.0 \pm 7.02$ & $35.05 \pm 3.77$ & $32.0 \pm 6.43$ \\
\hline
\end{tabular}




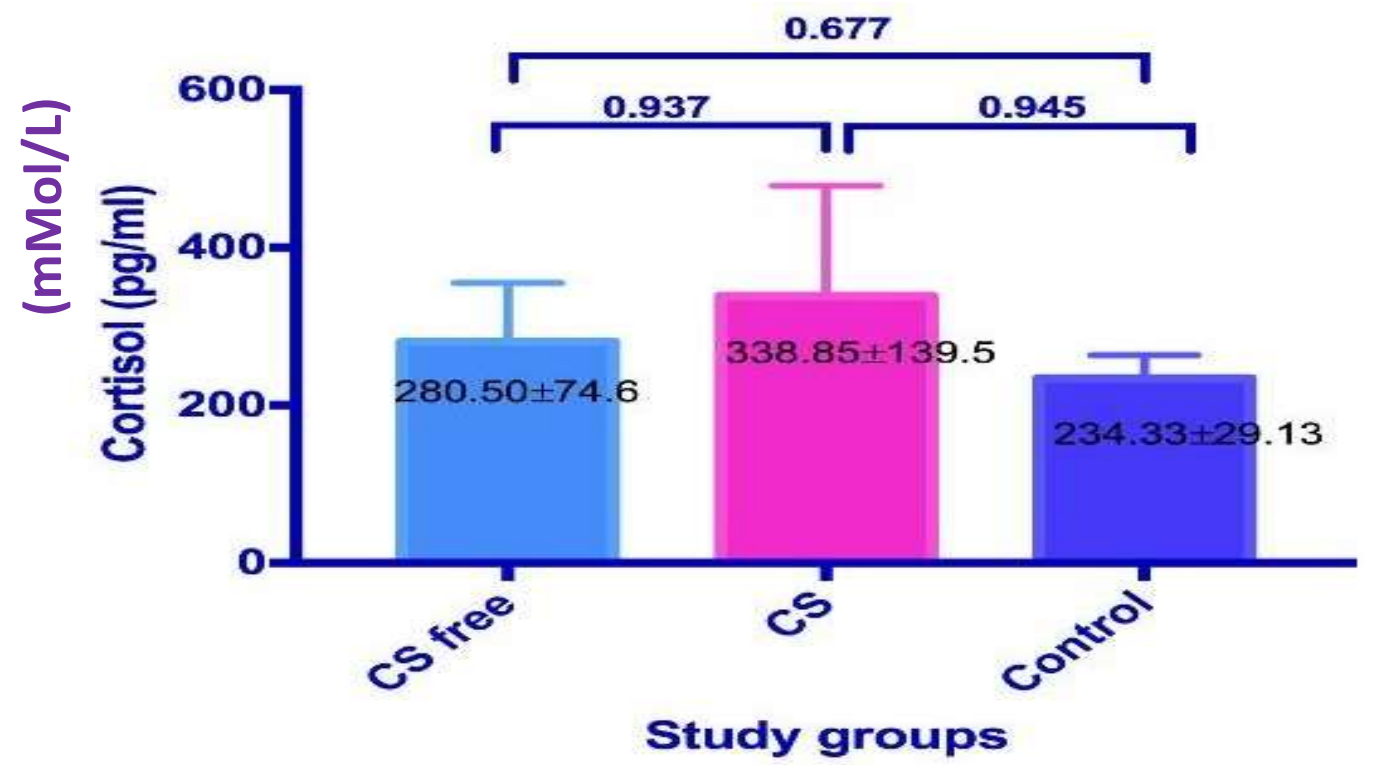

Figure 7-Mean \pm SE cortisol in the studied groups.

The mean of ACTH concentrations in steroid treated patients, steroid free patients and control subjects were $29.0 \pm 7.02 \mathrm{ng} / \mathrm{ml}, 35.05 \pm 3.77 \mathrm{ng} / \mathrm{ml}$ and $32.0 \pm 6.43 \mathrm{ng} / \mathrm{ml}$, respectively (Table-2).

ACTH hormone results demonstrated no significant differences between the studied groups (Figure-8).

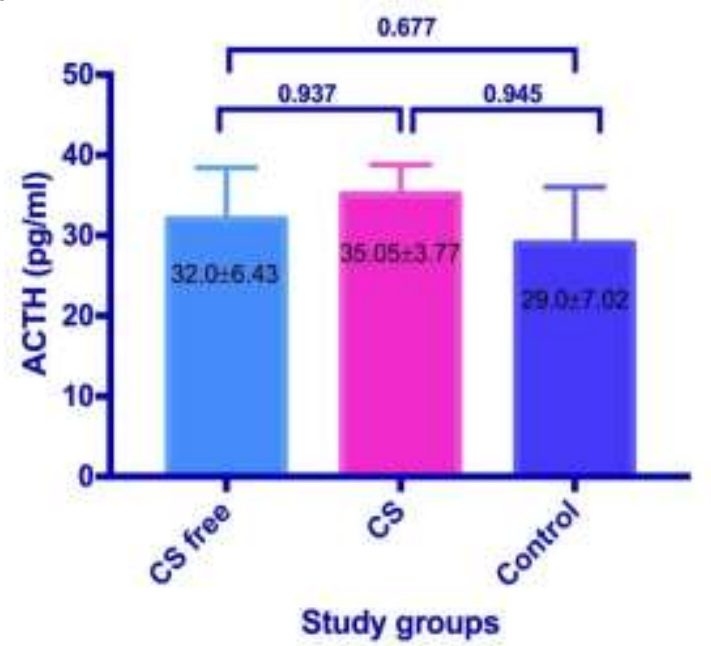

Figure 8-Mean \pm SE concentrations of ACTH in the studied groups.

\section{Discussion}

GR immunocytochemical analysis showed increased nuclear localization and decreased cytoplasmic subcellular localization in lymphocytes of asthmatic patients when compared with the control, while no significant differences were observed between the patients groups.

Glucocorticoids (steroids) were the best therapeutic drug used for treatment of inflammatory and allergic diseases, including asthma. GCs bind to cytoplasmic receptors and translocate to the nucleus, where they bind to glucocorticoid response element (GRE) in the promoter of glucocorticoid sensitive genes [13]. This leads to recruitment and activation of transcription co-activator molecules such as cyclic adenosine monophosphate binding protein (CBP) and steroid receptor coactivator 1 (SRC-1). These molecules have intrinsic histone acetylase activities (HAT) that result in acetylation of specific lysine residues on the core histone protein. As a result, a series of events take place such as chromatin remodeling, local unwinding of DNA, recruitment of RNA polymerase II, and transcription of antiinflammatory genes such as secretory leukoprotease inhibitor (SLPI), B2 adrenergic receptor, and CD163. 
The GR expression was reported to be the same in healthy and patients, but after stimulation it was found that GR nuclear translocation was lower in severe asthma as compared with non severe asthma and healthy volunteers[14], which agrees with our results of lower nuclear translocation in uncontrolled asthma .

The non steroid treated patients were also shown significantly increased nuclear translocation as compared to healthy donors, because that B2 agonist bronchodilator stimulated GR via ligand independent activation pathway, leading to C/EBP- $\alpha$ complex formation which amplifies the response [15].This was consistent with our results and those of other studies [16]which showed that GR nuclear translocation was decreased in asthma patients with poor steroid response.

FKBP51 co-chaperone is found in complex with HSP90 protein dynein, forming the multiunit GR. FKBP51 overexpression is induced by high concentrations of glucocorticoids as a negative feedback to downregulate the their harmful effects.FKBP51 was shown to be released from GR $\alpha$ and substituted with FKBP52upon binding to its ligand, and then GR $\alpha$ translocates to the nucleus [17], while Tajiri et al. reported that FKBP51 mediates nuclear translocation of GR $\alpha$ and GR $\beta$ without ligand binding[18]. In the present study, we found an increment in FKBP51 nuclear localization, associated with an uncontrolled status that might be related to GR $\beta$ which requires FKBP51 for nuclear translocation. This explains the increased nuclear GR localization with increased nuclear FKBP51 in lymphocytes and the reduced GC binding affinity and responsiveness to steroid treatment $[19,20]$

Also, non-steroid treated asthmatics including untreated patients and those treated with B2 agonist bronchodilator and leukotrienes modifiers (Monteleukast), were reported to have high levels of inflammatory cytokines and chemokines due to elevated levels of the transcription factor NF-қB that induces the inflammatory genes[21,22].

The activation of NF-қB is induced by proinflammatory cytokines such as ITNF $\alpha$ and IL-1 [23]. FKBP51 was suggested to activate ІқК which phosphorylates ІқВ and induces its split by proteosomal degradation. As a consequence, NF- $\mathrm{B}$ translocates to the nucleus and activates inflammatory genes. Zannas and his associates revealed the role of FKBP51 in immune related diseases like rheumatoid arthritis, COPD and asthma, which is associated with NF-қB dependent FKBP51 activation [24].The FKBP51- ІқK complex was shown to be increased in inflammations, based on the following steps: 1) Increase of the phosphorylation of Іқ B; 2) Dislocation of Іқ B by ubiquitination and proteosomal degradation; 3) NF-қB (p50/p65) translocation to the nucleus; 4) Stimulation of the transcription of inflammatory genes, increasing the inflammation, induction of the immune response and autophagy and reduction of the apoptosis [25].

HPA axis functions normally in asthma patients, while it may be activated with a rise in cortisol level corresponding to the degree of stress [26], which was higher in poor-controlled than controlled patients.

The non significant increase in cortisol level in patients was consistent with the results of Adcock and Mumby [27]who found that inhaled steroid causes non significant reduction in cortisol level. They also reported that high doses of inhaled corticosteroids (Budesonide dipropionate) were effective for asthma management but did suppress cortisol secretion. Inhaled corticosteroids (ICs) form the gold standard first line therapy in effective management of persist asthma and reduction of morbidity and mortality.

Most well-known side effects of high doses of CS is suppression of Hypothalamus -Pituitary Adrenal axis (HPA) which was indicated by the decrease in serum or urine cortisol. Therefore, cortisol may be a relevant surrogate marker to identify the potential for adverse effects [28].

Most of HPA dysfunction and adrenal suppression are associated with oral corticosteroid OCS reach up to $80 \%$ [29] and less degree caused by ICS use about less than $40 \%$ depending on bioavailability related to dose, delivery device, particle size and lung versus upper airway deposition[30]

The decreased ACTH level in steroid-treated asthmatics results were in agreement with the results reported by Rebeccat and associates who showed that ACTH level was decreased due to the steroid treatment-associated negative feedback that inhibited the HPA axis (CRH, ACTH, and Cortisol), in addition to the long term treatment that causes secondary adrenal Insufficiency [31].

Oral or high doses of inhaled corticosteroids block the release of CRH and ACTH and then lower cortisol level. This Insufficiency continued even after treatment cessation for more than one year, with 
no significant difference between non steroid treated patients and the control subjects, while the results were within the reference range [32].

However, Zollner found that HPA suppression could be reversed by reducing the steroid levels and modified by adding other asthmatic treatments (LABA), and that the patients'improvement time was correlated with ACT [33].

\section{References}

1. Brooks, C.R., Van Dalen, C.J., Harding, E., Hermans, I.F. and Douwes, J. 2017. Effects of treatment changes on asthma phenotype prevalence and airway neutrophil function. BMC pulmonary medicine. 17(1): 169.

2. Kang, C.B., Hong, Y., Dhe-Paganon, S. and Yoon, H.S. 2008. FKBP family proteins: immunophilins with versatile biological functions. Neurosignals. 16(4): 318-325.

3. Woodruff, P.G., Boushey, H.A., Dolganov, G.M., Barker, C.S., Yang, Y.H., Donnelly, S., Ellwanger, A., Sidhu, S.S., Dao-Pick, T.P. and Pantoja, C. 2007. Genome-wide profiling identifies epithelial cell genes associated with asthma and with treatment response to corticosteroids. Proceedings of the National Academy of Sciences. 104(40): 15858-15863.

4. Vermeer, H., Hendriks-Stegeman, B.I., van der Burg, B., van Buul-Offers, S.C. and Jansen, M. 2003. Glucocorticoid-induced increase in lymphocytic FKBP51 messenger ribonucleic acid expression: a potential marker for glucocorticoid sensitivity, potency, and bioavailability. The Journal of Clinical Endocrinology \& Metabolism. 88(1): 277-284.

5. Rhodes, M.E. 2017. Adrenocorticotropic Hormone, in Stress: Neuroendocrinology and Neurobiology. Copyright ( 2017 Elsevier Inc. : Academic Press.p. 109-116.

6. Lim, C.T. and Khoo, B. 2017. Normal physiology of ACTH and GH release in the hypothalamus and anterior pituitary in man, in Endotext [Internet]. MDText. com, Inc.

7. Willenberg, H. and Bornstein, S. 2017.Adrenal Cortex; Development, Anatomy, Physiology. in Endotext [Internet]. C.G. In: De Groot LJ, Dungan K, et al., editors. , Editor. .: MDText.com, Inc.; 2000: South Dartmouth (MA).

8. Cain, D.W. and Cidlowski, J.A. 2017. Immune regulation by glucocorticoids. Nature Reviews Immunology. 17(4): 233.

9. Patil, B., Eti, A., Lolly, M., Khan, S. and Bansal, A. 2018. A clinical evaluation of asthma control test to assess the control of asthma and its relation to the severity of asthma. International Journal of Health \& Allied Sciences. 7(1): 12.

10. Boyum, A. 1968. Separation of leukocytes from blood and bone marrow. Scand. J. clin. lab. Invest. 21: 77.

11. Mendez-David, I., El-Ali, Z., Hen, R., Falissard, B., Corruble, E., Gardier, A., Kerdine-Romer, S. and David, D. 2013. A method for biomarker measurements in peripheral blood mononuclear cells isolated from anxious and depressed mice: $\beta$-arrestin 1 protein levels in depression and treatment. Frontiers in Pharmacology. 4(124).

12. Antakly, T., O'Donnell, D. and Thompson, E.B. 1990.Immunocytochemical localization of the glucocorticoid receptor in steroidsensitive and-resistant human leukemic cells. Cancer research. 50(4): 1337-1345.

13. Adcock, I.M., Ito, K. and Barnes, P.J. 2004. Glucocorticoids: effects on gene transcription. Proceedings of the American Thoracic Society. 1(3): 247-254.

14. Chang, P.-J., Michaeloudes, C., Zhu, J., Shaikh, N., Baker, J., Chung, K.F. and Bhavsar, P.K. 2015. Impaired nuclear translocation of the glucocorticoid receptor in corticosteroid-insensitive airway smooth muscle in severe asthma. American journal of respiratory and critical care medicine. 191(1): 54-62.

15. Black, J.L., Oliver, B.G. and Roth, M. 2009. Molecular mechanisms of combination therapy with inhaled corticosteroids and long-acting $\beta$-agonists. Chest. 136(4): 1095-1100.

16. Alizadeh, Z., Mazinani, M., Mortaz, E., Fazlollahi, M.R., Adcock, I. and Moein, M. 2018. Glucocorticoid Receptor Nuclear Translocation in CD4 T Cells from Severe and Moderate Asthmatic Patients Treated with Fluticasone/Vilanterol. Iranian Journal of Allergy, Asthma and Immunology. 17(1): 1-8.

17. Zgajnar, N.R., De Leo, S.A., Lotufo, C.M., Erlejman, A.G., Pilipuk, G.P. and Galigniana, M.D. 2019. Immunophilins FKBP51 and FKBP52. Biomolecules. 9(2): 52. 
18. Tajiri, T., Matsumoto, H., Niimi, A., Ito, I., Oguma, T., Nakaji, H., Inoue, H., Iwata, T., Nagasaki, T. and Kanemitsu, Y. 2013. Association of eosinophilic inflammation with FKBP51 expression in sputum cells in asthma. PLoS One. 8(6): e65284.

19. Barnes, P.J. 2013. Corticosteroid resistance in patients with asthma and chronic obstructive pulmonary disease. Journal of Allergy and Clinical Immunology. 131(3): 636-645.

20. Hamid, Q.A., Wenzel, S.E., Hauk, P.J., Tsicopoulos, A., Wallaert, B., Lafitte, J.-j., Chrousos, G.P., Szefler, S.J. and Leung, D.Y. 1999. Increased glucocorticoid receptor $\beta$ in airway cells of glucocorticoid-insensitive asthma. American journal of respiratory and critical care medicine. 159(5): 1600-1604.

21. Liu, X., Lin, R., Zhao, B., Guan, R., Li, T. and Jin, R. 2016. Correlation between oxidative stress and the NF- $\mathrm{KB}$ signaling pathway in the pulmonary tissues of obese asthmatic mice. Molecular medicine reports. $\mathbf{1 3}(2)$ : 1127-1134.

22. Schuliga, M. 2015. NF-kappaB signaling in chronic inflammatory airway disease. Biomolecules. 5(3): 1266-1283.

23. Serasanambati, M. and Chilakapati, S.R. 2016. Function of nuclear factor kappa B (NF-kB) in human diseases-a review. South Indian Journal of Biological Sciences. 2(4): 368-387.

24. Zannas, A.S., Wiechmann, T., Gassen, N.C. and Binder, E.B. 2016. Gene-stress-epigenetic regulation of FKBP5: clinical and translational implications. Neuropsychopharmacology. 41(1): 261.

25. Daudt, D.R. and Yorio, T. 2011. FKBP51 protects $661 \mathrm{w}$ cell culture from staurosporine-induced apoptosis. Molecular vision. 17: 1172.

26. Kapoor, U., Tayal, G., Mittal, S., Sharma, V. and Tekur, U. 2003. Plasma cortisol levels in acute asthma. The Indian Journal of Pediatrics. 70(12): 965-968.

27. Adcock, I.M. and Mumby, S. 2016. Glucocorticoids, in Pharmacology and Therapeutics of Asthma and COPD. Springer. p. 171-196.

28. Barra, C.B., Fontes, M.J.F., Cintra, M.T.G., Cruz, R.C., Rocha, J.A., Guimarães, M.C.C. and Silva, I.N. 2017. Oral corticosteroids for asthma exacerbations might be associated with adrenal suppression: Are physicians aware of that? Revista da Associação Médica Brasileira. 63(10): 899-903.

29. Aljebab, F., Choonara, I. and Conroy, S. 2017. Systematic review of the toxicity of long-course oral corticosteroids in children. PLoS One. 12(1): e0170259.

30. Issa-El-Khoury, K., Kim, H., Chan, E.S., Vander Leek, T. and Noya, F. 2015. CSACI position statement: systemic effect of inhaled corticosteroids on adrenal suppression in the management of pediatric asthma. Allergy, Asthma \& Clinical Immunology. 11(1): 9.

31. Joseph, R.M., Hunter, A.L., Ray, D.W. and Dixon, W.G. 2016. Systemic glucocorticoid therapy and adrenal insufficiency in adults: A systematic review. in Seminars in arthritis and rheumatism. Elsevier.

32. Gangadharan, A., McCoy, P., Phyo, A., McGuigan, M.P., Dharmaraj, P., Ramakrishnan, R., McNamara, P.S. and Blair, J. 2017. Recovery of hypothalamo-pituitary-adrenal axis suppression during treatment with inhaled corticosteroids for childhood asthma. Journal of asthma and allergy. 10: 317.

33. Zöllner, E. 2018. Is adrenal suppression in asthmatic children reversible? A case series. South African Medical Journal. 108(6): 502-505. 